\title{
Alternative Technique for Suture in Surgeries of Edentulous Mandibles
}

\section{Geninho Thomé, Thomas Berry ${ }^{2}$, Larissa Carvalho Trojan ${ }^{3}$, Carolina Accorsi Cartelli $^{4}$, Marcos Boaventura de Moura $^{5^{*}}$ and Sergio Rocha Bernardes ${ }^{6}$}

${ }^{1}$ Department of Implantology, Faculty Ilapeo, Brazil

${ }^{2}$ Implantologist, Private Clinic, Clear Choice Atlanta, Atlanta, Georgia, USA

${ }^{3}$ Department of Implantology, Faculty Ilapeo, Brazil

${ }^{4}$ Department of Implantology, Faculty Ilapeo, Brazil

${ }^{5}$ Faculty of Dentistry, Department of Occlusion, Fixed Prosthodontics and Dental Materials, Federal University of Uberlandia, Brazil

${ }^{6}$ Department of Implantology, Faculty Ilapeo, Brazil

*Corresponding author: Marcos Boaventura de Moura, PhD Student, Faculty of Dentistry, Department of Occlusion, Fixed Prosthodontics and Dental Materials, Federal University of Uberlandia, Uberlandia, MG, Brazil, Tel: +55 41 997666978/ Fax: +554135956000 .

\begin{abstract}
The surgical procedure for dental implants presents predictable long-term results. An important part of the surgical procedure is suture, which plays an important role in healing, reconstructing and remodeling soft tissue and promoting hemostasis of the region. The purpose of this case report is to introduce an alternative technique for performing suture in implant surgery of lower total arch. Four implants were placed in the patient's lower jaw, all with a minimum torque of $60 \mathrm{Ncm}$. A small perforation it was performed in the lingual/buccal face of alveolar bone, between implants previously placed, using a straight handpiece with a $1.1 \mathrm{~mm}$ diameter drill at a 45 degrees inclination to the bone platform. Suture it was performed with mononylon (from the buccal soft tissue to the channel created (towards the lingual bone) and was closed through the lingual soft tissue. This procedure can be done between all implants placed. On the third day, the inferior protocol was installed and simultaneous bilateral contacts were adjusted. This suture reduces the possibility of penetration of impression material into implant surgeries with immediate prosthetic rehabilitation. It might reduces the risk of infection and promotes faster healing. After 12 months of follow-up the implants and prosthesis were in good condition, maintaining the rehabilitation success.
\end{abstract}

\section{Keywords}

Dental implantation, Dental prosthesis, Surgery, Sutures

\section{Introduction}

Surgery for dental implants placement is a known and safe procedure, with predictable results in the long term [1,2]. Implant survival and success rate in full edentulous patients are high, independent of the loading protocol followed, if conventional, delayed or immediate [3-5]. Multiple aspects must to be controlled during a surgery in order to have success and suture is one of them. A proper and stable suture results in better tissue healing and right biological reactions. Suture plays an important role in healing, enabling reconstruction and reassembly of the soft tissue separated by the surgical procedure and at the same time facilitate and promote healing and hemostasis [6].

In case of immediate loading procedures, correct suturing avoids impression material penetration and facilitates the prosthetic hygiene. Wound dehiscence after surgeries compromise the potential of reparation and

Citation: Thomé G, Berry T, Trojan LC, Cartelli CA, de Moura MB, et al. (2019) Alternative Technique for Suture in Surgeries of Edentulous Mandibles. Int J Oral Dent Health 5:102. doi.org/10.23937/24695734/1510102

Accepted: October 25, 2019: Published: October 28, 2019

Copyright: (c) 2019 Thomé G, et al. This is an open-access article distributed under the terms of the Creative Commons Attribution License, which permits unrestricted use, distribution, and reproduction in any medium, provided the original author and source are credited. 


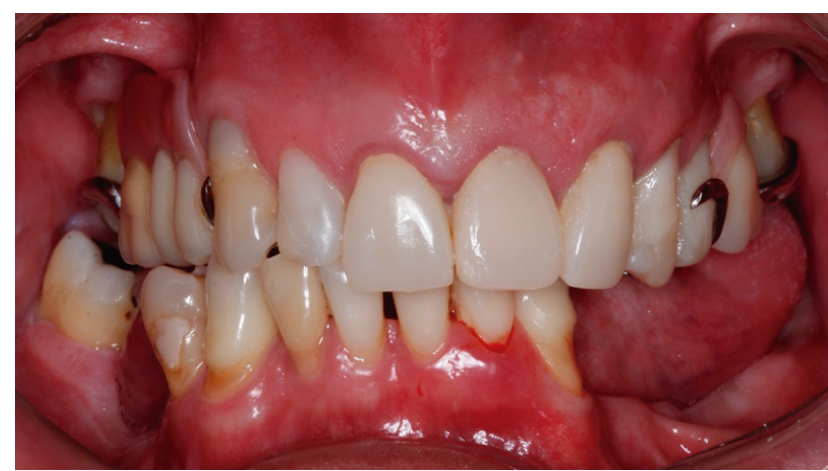

Figure 1: Clinical image showing the initial oral condition of the patient.

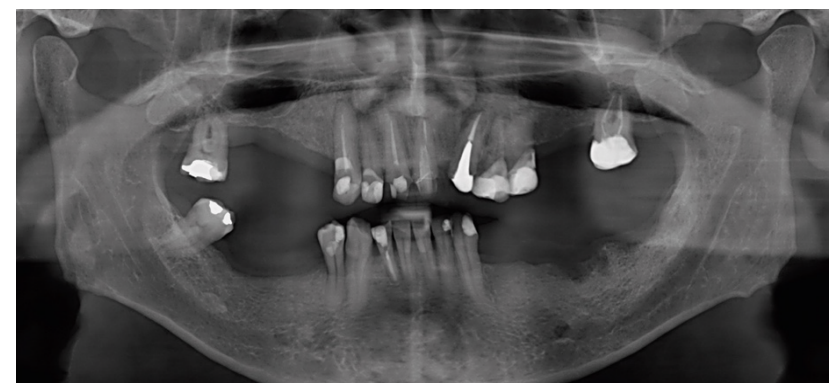

Figure 2: Preoperative panoramic radiography.

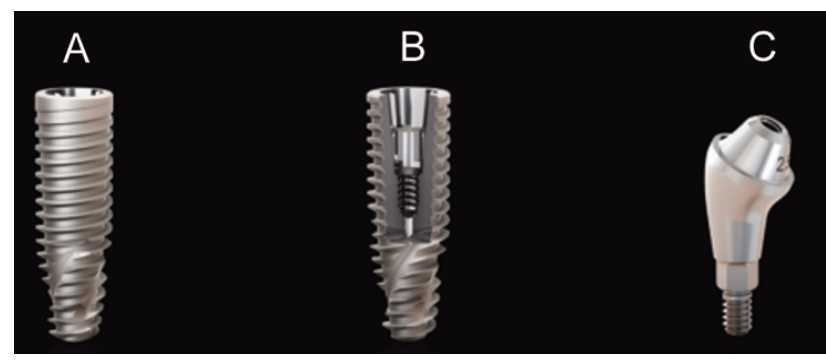

Figure 3: A,B) Helix Grand Morse Acqua implant (Neodent, Curitiba, Brazil); C) Mini conical angled abutment (Neodent).

regeneration, increasing implant crestal bone loss [7] and the risk of infection [8].

Well known full arch technique treatment has been used for protocols of immediate loading. This technique involves the placement of four implants for rehabilitation of fully edentulous dental arches and with diminished bone volume. The implants should be well anchored, tilted 45 degrees (achieving a primary stability of at least $30 \mathrm{Ncm}$ ). The success rate for this technique has been described with a high success rate $(98 \%$ for the maxilla and $98.1 \%$ for the mandible after 5 to 10 years of follow-up [9].

As transosseous suture is a technique commonly used in orthopedics in order to reapproximate tissues and adequate closure of the surgical wound is one of the most important aspects of an implant surgery [10]. The aim of this communication is to introduce an alternative technique for suture after a full arch implant surgery, reducing incidences of wound dehiscence.

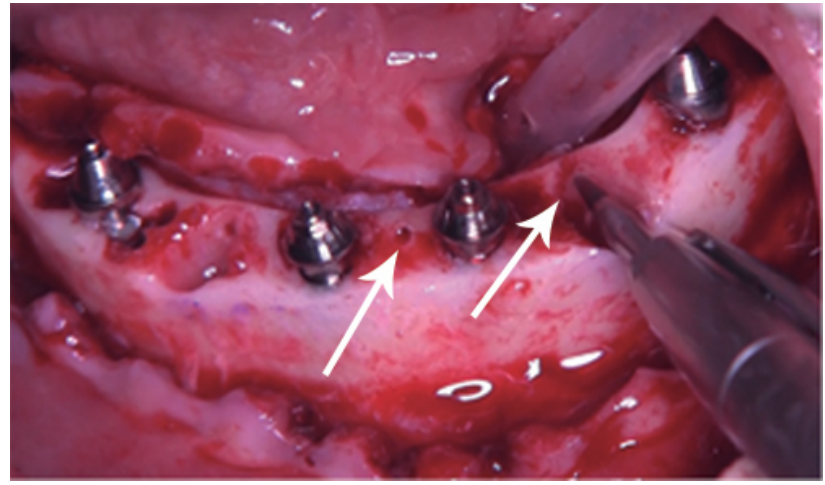

Figure 4: Perforation performed in the lingual/buccal face of alveolar bone, between implants previously placed, using a straight handpiece with a $1.1 \mathrm{~mm}$ diameter.

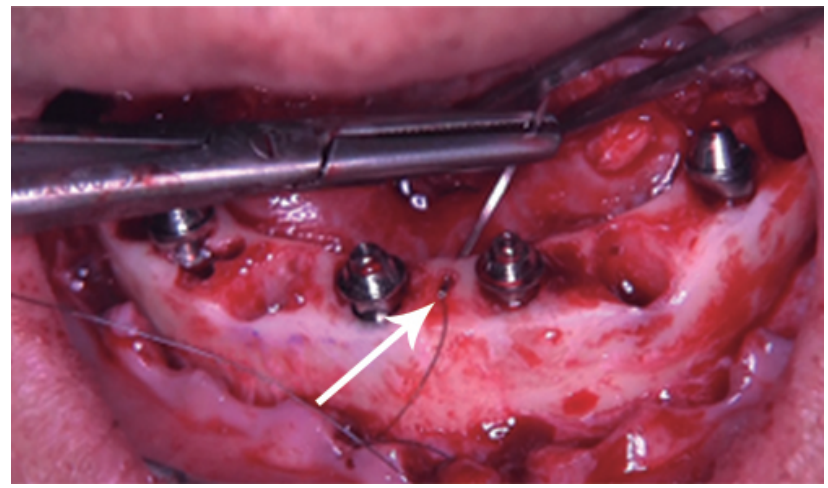

Figure 5: Needle passing through the soft lingual tissue.

\section{Case Report}

A 52-year-old man presented at the Oral Implant Dentistry Department of the Faculty Ilapeo, Curitiba, Brazil. The same complained of generalized mobility in the lower teeth. At the first moment, anamnesis and radiographic examination were performed. At the time of the clinical and radiographic examination was noted the presence of periodontal disease with points of exacerbation, generalized bone loss and mobility grade 2 in teeth (Figure 1 and Figure 2). It was suggested the extraction of the inferior dental elements for placement of dental implants and installation of a denture about implants with immediate loading.

The implants selected for this case present some important characteristics: 1) Hybrid conical implants with compacting threads in the coronal area and cutting threads in the medial and apical third; 2) Double threads for minimal trauma and faster placement; 3) Conical apex with low-activity cameras and helical flutes designed to optimize primary stability. Regarding the abutments, it was installed Grand mini conical angled abutment which has an anatomical design to improved soft tissue accommodation (Figure 3).

After the local anesthesia, supracrestal and oblique incision and detachment of the flap was performed, and 


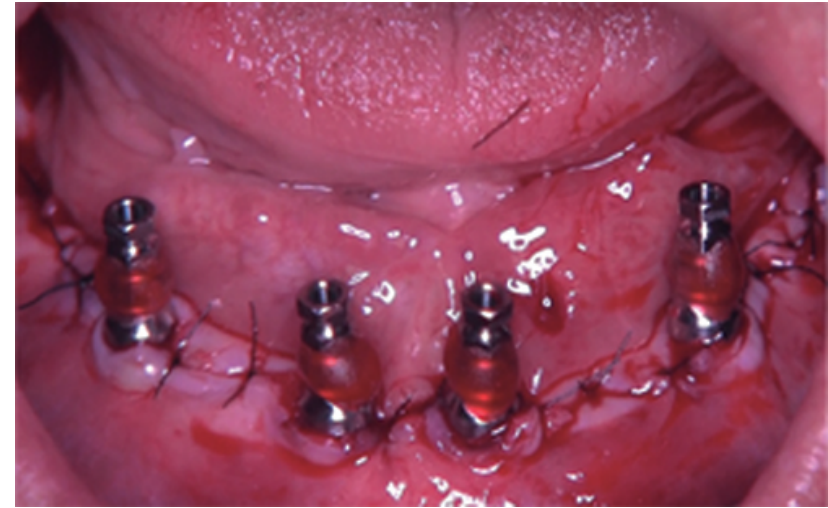

Figure 6: Suture of the finished region.

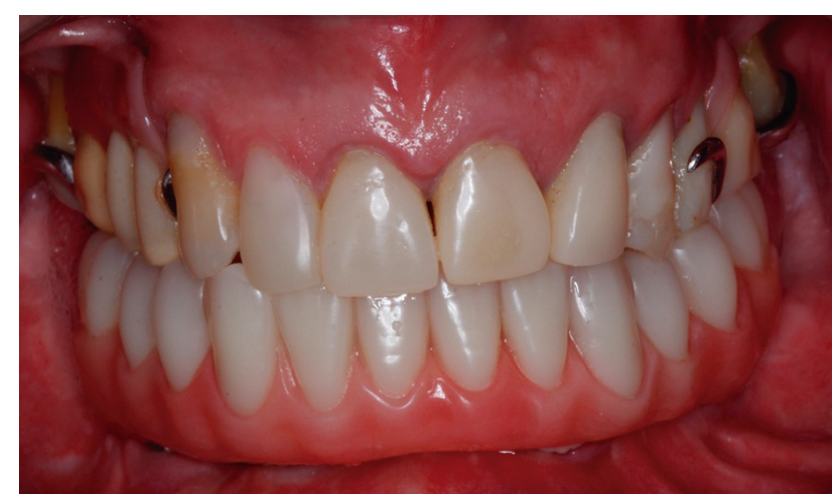

Figure 7: Final condition of the patient with the inferior prosthesis installed.

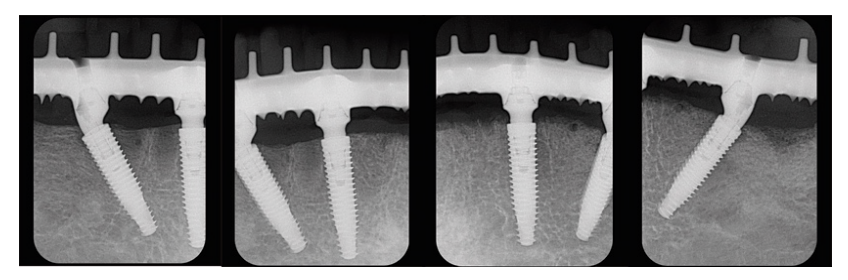

Figure 8: Healing around the mini-abutments after 12 months of surgery.

after alveolar bone regularization, the proper implant length was checked. Multiple teeth extractions were performed and the drill sequence was followed by conical drill $3.5 \mathrm{~mm}, 3.75 \mathrm{~mm}$ and conical contour 3.75 drill. Four implants Helix GM Aqua $4.0 \times 16 \mathrm{~mm}$ (Neodent) were placed $2 \mathrm{~mm}$ subcrestal, all with minimum torque of $60 \mathrm{Ncm}$. Four mini conical abutments (Neodent) were installed at $2.5 \mathrm{~mm}$ of gengiva height (Straight abutment for the anterior implants and 17 degrees angled in the posterior implants). A small perforation was performed in the lingual/buccal face of alveolar bone, between implants previously placed, using a straight handpiece with a $1.1 \mathrm{~mm}$ diameter drill for grafting screws, (Neodent) at a 45 degrees inclination to the bone platform (Figure 4).

Suture was performed with mononylon (4-0, J\&J Ethicon, Cincinnati, USA) from the buccal soft tissue to the channel created (towards the lingual bone) and was closed through the lingual soft tissue (Figure 5 and Figure 6).

This procedure should be done between all implants placed. After suturing the mandibular region, impression copings were positioned in the mini conical abutments and attached to the multifunctional guide by acrylic Pattern Resin (GC America Inc, Alsip, USA). With the upper and lower guides in position, a 3-point occlusal registration was performed considering the vertical dimension previously determined. The impression was done with condensation silicone Speedex (Coltene, Altstätten, Switzerland). The impression copings were unscrewed, the impression was removed and sent to the laboratory for manufacture the metal bars and the teeth assembly (Figure 6). The prosthesis was acrylated and installed in the third postoperative day. The occlusal adjustment was performed maintaining bilateral stability at maximum intercuspation, contacts and occlusal forces equally distributed, anterior guide and smooth lateral mandibular excursions without work-side and non-working interferences.

The suture was removed 15 days after surgery and oral hygiene orientation was performed.

The clinical and radiographic control was done after 1, 2, 3, and 4 and 12 months (Figure 7 and Figure 8).

\section{Discussion}

The presence of a marginal space between the implant and the abutment may lead to greater marginal bone loss due to the penetration of bacteria at the implant-abutment interface [11]. The conical implant-abutment systems have delayed or even prevented bacterial colonization through the use of the platform switching concept, resulting in improved implant system performance $[11,12]$. Another important point is the precision of the adjustment or passive adaptation, and several factors can influence the final adaptation: The structure of the wax pattern, the casting process, the production of the final prosthesis and the delivery of the same [13].

Over the years complications associated with misfit in the prosthesis-implant or implant-abutment structure have been reported, such as: Mechanical failures, pillar rotation, loosening or fracture of prosthetic screws, poor distribution of forces and biological failure, such as adverse tissue reactions, sensitivity and pain [14]. However, peri-implant bone remodeling seems to alleviate the magnitude of the misfit, implying that structural misfit is not the cause of bone resorption and loss of implants [15].

The success of the immediate loading can be partially attributed to the splinting effect provided by a full bar, joining all the implants, the rigorous oral hygiene regime and the standardization of surgical and prosthetic procedures [16]. The short-term success 
of immediate loading in mandibular protocols was comparable to that of late loading protocols [15]. Papaspyridakos, et al. [17] suggested the immediate loading as an excellent alternative to overcome the problems of conventional loading. The technique proposed in this case may exemplify an alternative to rehabilitate our patients in a less morbid way. The present study demonstrated excellent stability of implants with immediate loading over a period of 12 months, without early failure and complications.

\section{Conclusions}

A modified suture was presented, which reduces the possibility of penetration of impression material in implant surgeries with immediate prosthetic rehabilitation. It might reduces the risk of infection and promotes faster healing. After 12 months of follow-up, the implants and prosthesis were in good condition, maintaining healthy of soft tissue and bone around the implant platform. More studies are needed with a greater number of patients and longer time of proservation.

\section{Ethics Approval}

A consent form to publish the case with the clinical photography and radiography was signed by the patient.

\section{Disclosures}

This research did not receive any specific grant from funding agencies in the public sectors.

\section{Conflict of Interest}

The authors Thomé G, Trojan LC, Cartelli CA, Moura $\mathrm{MB}$, Bernardes SB declare a conflict of interest. Both authors work at Neodent, manufacturer of the implants and components used in this case report. However, the authors had no influence on the results.

\section{Statement of Equal Authors' Contribution}

Thome G: contributed with the conception of the work; data acquisition and analysis, drafting the work; and final approval of the work. Berry $\mathrm{T}$ : contributed with data acquisition; drafting; and final approval of the work. Thomé $\mathrm{G}$ and Trojan CL: contributed with data acquisition; drafting; and final approval of the work. Trojan $\mathrm{CL}$ : contributed to the conception of the work; revising; and final approval of the work. Cartelli CA: contributed with data acquisition; drafting; and final approval of the work. Moura MB and Bernardes SB: contributed to the conception of the work; revising; and final approval of the work.

\section{References}

1. Branemark PI, Hansson BO, Adell R, Breine U, Lindstrom $\mathrm{J}$, et al. (1977) Osseointegrated implants in the treatment of the edentulous jaw. Experience from a 10-year period. Scand J Plast Reconstr Surg Suppl 16: 1-132.
2. Adell R, Lekholm U, Rockler B, Branemark PI (1981) A 15year study of osseointegrated implants in the treatment of the edentulous jaw. Int J Oral Surg 10: 387-416.

3. Schnitman PA, Wohrle PS, Rubenstein JE (1990) Immediate fixed interim prostheses supported by two-stage threaded implants: Methodology and results. J Oral Implantol 16: 96-105.

4. Schnitman PA, Wöhrle PS, Rubenstein JE, DaSilva JD, Wang NH (1997) Ten-year results for Brånemark implants immediately loaded with fixed prostheses at implant placement. Int J Oral Maxillofac Implants 12: 495-503.

5. Chrcanovic BR, Albrektsson T, Wennerberg A (2014) Immediate nonfunctional versus immediate functional loading and dental implant failure rates: A systematic review and meta-analysis. J Dent 42: 1052-1059.

6. Brandt MT, Jenkins WS (2012) Suturing principles for the dentoalveolar surgeon. Dent Clin North Am 56: 281-303.

7. Soheilifar S, Bidgoli M, Abbasi Atibeh E, Faradmal J (2016) Radiographic evaluation of bone-level implants with wound dehiscence between the first- and second-stage surgeries. J Long Term Eff Med Implants 26: 245-251.

8. Matalon S, Kozlovsky A, Kfir A, Levartovsky S, Mazor Y, et al. (2013) The effect of commonly used sutures on inflammation inducing pathogens-an in vitro study. J Craniomaxillofac Surg 41: 593-597.

9. Maló P, de Araújo Nobre M, Lopes A, Francischone C, Rigolizzo M (2012) All-on-4 immediate-function concept for completely edentulous maxillae: A clinical report on the medium (3 years) and long-term (5 years) outcomes. Clin Implant Dent Relat Res 14: 139-150.

10. Panagopoulos A, Tatani I, Yannis S, Aikaterini B, Kouzelis A, et al. (2018) Transosseous suture fixation of true 4-part valgus impacted fractures of the proximal humerus: Clinical and radiological outcome in 49 patients. Open Orthop J 12: 41-52.

11. Merz BR, Hunenbart S, Belser UC (2000) Mechanics of the implant-abutment connection: An 8-degree taper compared to a butt joint connection. Int J Oral Maxillofac Implants 15: 519-526.

12. Tesmer M, Wallet S, Koutouzis T, Lundgren T (2009) Bacterial colonization of the dental implant fixture-abutment interface: An in vitro sudy. J Periodontol 80: 1991-1997.

13. Abduo J, Judge RB (2014) Implications of implant framework misfit: A systematic review of biomechanical sequelae. Int J Oral Maxillofac Implants 29: 608-621.

14. Kano SC, Binon PP, Curtis DA (2007) A classification system to measure the implant-abutment microgap. Int $\mathrm{J}$ Oral Maxillofac Implants 22: 879-885.

15. Alsabeeha N, Atieh M, Payne AG (2010) Loading protocols for mandibular implant overdentures: A systematic review with meta-analysis. Clin Implant Dent Relat Res 12: 28-38.

16. Chiapasco M (2004) Early and immediate restoration and loading of implants in completely edentulous patients. Int $\mathrm{J}$ Oral Maxillofac Implants 19: 76-91.

17. Romanos GE, Gupta B, Eckert SE (2012) Distal cantilevers and implant dentistry. Int $\mathrm{J}$ Oral Maxillofac Implants 27: 1131-1136.
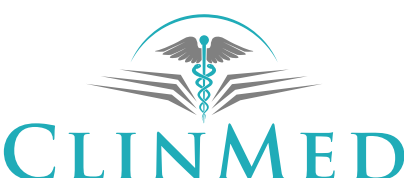

INTERNATIONAL LIBRARY 